\title{
A COVID-19 Risk Reduction Assessment for a Health-Care Employee from an Ethnic Background: A Case Study in the United Kingdom
}

\author{
Laran Chetty \\ Occupational Health and Wellbeing Centre, Royal Free London NHS Foundation Trust, London, UK
}

\section{Keywords}

Coronavirus disease-2019 · Employee · Ethnic · Health-care · Risk reduction assessment

\begin{abstract}
Concerns in the United Kingdom (UK) that Black, Asian and Minority Ethnic (BAME) populations have disproportionately higher rates of coronavirus disease 2019 (COVID-19) than white populations have led to ethnicity being identified as a risk factor within the latest guidance from Public Health England. The purpose of this case report was to determine whether the risk reduction assessment would aid the line manager support a BAME health-care employee who was concerned that his ethnicity put him at greater risk of contracting COVID-19. This report described the case, protocol, and outcome of undertaking a risk reduction assessment. It is concluded that the risk reduction assessment may assist line managers implement appropriate adjustments for BAME employees in order to alleviate their concerns and mitigate the risks of COVID-19.

(c) 2021 The Author(s) Published by S. Karger AG, Basel
\end{abstract}

(C) 2021 The Author(s)

Published by S. Karger AG, Basel

This article is licensed under the Creative Commons AttributionNonCommercial-NoDerivatives 4.0 International License (CC BY NC-ND) (http://www.karger.com/Services/OpenAccessLicense) Usage and distribution for commercial purposes as well as any distribution of modified material requires written permission.

\section{Introduction}

Ethnicity as a risk factor has been included in the latest guidance from Public Health England because of concerns in the United Kingdom (UK) that Black, Asian and Minority Ethnic (BAME) populations have disproportionately higher rates of coronavirus disease 2019 (COVID-19) than white populations [1]. An emerging finding from the data in the UK indicated that particular comorbidities, for instance diabetes, $\mathrm{CKD}$, cardiovascular disease, and hypertension, are more common in individuals that experience severe symptoms of COVID-19 [2]. Such comorbidities tend to be more common in populations that identify themselves as BAME and is often used as an explanation for the higher prevalence of morbidity and mortality within this community [1].

However, other evidence has attributed social and economic inequalities rather than genetics on the number of BAME populations being infected by COVID-19. For example, those from a BAME background are more likely to be affected by poverty in the UK, particularly those from Black African, Pakistani, and Bangladeshi backgrounds [3]. Poverty limits healthy choices for people and has an impact on overall health, ability to access care, and living arrangements. Overcrowded housing is more likely to be 
experienced by BAME populations in all socioeconomic groups [4]. Although there may be some health and wellbeing benefits in terms of reduced social isolation, there are health risks associated with overcrowding, particularly when it comes to infectious diseases like COVID-19. Reduced ability to socially distance may increase the chance of exposure to a higher dose of the virus whether it is through overcrowded housing or the choice to live as a multigenerational family. Furthermore, this incidence and mortality due to COVID-19 is notably distinctive among health-care employees who identify as BAME within the UK [5]. In the National Health Service (NHS), there are between 1.2 and 1.5 million employees of which BAME employees account for approximately $21 \%$ [6].

The purpose of undertaking the risk reduction assessment was to determine whether the risk reduction assessment would aid the line manager support a BAME healthcare employee who was concerned that his ethnicity put him at greater risk of contracting COVID-19, by making an assessment of personnel and workplace factors as part of an overall risk management and reduction strategy.

\section{Case Report}

A case is presented of a 57-year-old male BAME health-care employee working full time in a patient facing role. He has worked for the NHS Trust for approximately 14 years. He has a past history of anxiety and depression and hypertension, all of which are currently under control. Socially, he lives with his wife and 2 young children. He works a regular 37.5-h week, Monday-Friday, 08:3017:00 shift pattern. He reported to his manager that his current job role is making him anxious and felt that he is at risk of contracting COVID-19, despite the safety measures already in place (i.e., social distancing and face masks). He was particularly concerned that his ethnicity put him at greater risk than his white colleagues. His manager contacted a occupational health worker who advised to complete a risk reduction assessment.

\section{Risk Assessment Protocol}

All NHS employees are required to complete the risk reduction assessment, but it is particularly important for BAME employees due to the increase in vulnerability to COVID-19. The risk reduction assessment complemented existing health and safety guidance and included 5 risk factors, namely, age, sex, underlying health conditions, ethnicity, and pregnancy [7].

\section{Age}

Public Health England has established that those over the age of 55 yeras are clinically vulnerable and are required to self-isolate.

Sex

Emerging data from the UK show that COVID-19 disproportionately affects men, with three-fifths of patients entering into hospitals identify as male.
Underlying Health Conditions

Those presenting with underlying conditions are at increased risk, in particular those with diabetes, CKD, cardiovascular disease, and hypertension.

\section{Ethnicity}

BAME populations present with a higher level of risk, especially those presenting with comorbidities and those who are of a younger age presenting with poor health outcomes.

\section{Pregnancy}

Pregnant woman are regarded as high risk and are advised to stay at home if they are over 28 weeks.

The risk reduction assessment can be completed by the line manager or supervisor, who can be supported by the Clinical Governance Facilitator or Health and Safety Representative. The risk reductions assessment must be recorded and reviewed if needed. The outcome of the risk reduction assessment was divided into 3 categories, namely, low risk (area where patients with COVID-19 are unlikely to be assessed or admitted); moderate risk (area where patients with COVID-19 are expected to be assessed or admitted); and high risk (aerosol generating procedures on confirmed/suspected COVID-19 patients). After the outcome is determined, an agreed action plan is implemented by taking into account the key personnel and workplace factors in line with the overall risk reduction and management strategy.

\section{Outcome}

Following completion of the risk reduction assessment, the employee was classified as high risk. This was because the employee presented with 4 risk factors, namely, being male, of BAME ethnicity, $>55$ years of age, and presenting with underlying health conditions. Furthermore, the employee worked in an area where patients with COVID-19 can be reasonably expected to be assessed. Based on the finding of the risk reduction assessment, this employee was offered a temporary redeployment to a non-patient facing role with the option of working from home on certain days. The employee agreed to be redeployed for a period of 3 months and a review date was set 2 weeks before this period was due to expire.

\section{Discussion}

The purpose of this case report was to determine whether the risk reduction assessment would aid the line manager support a BAME healthcare employee who was concerned that his ethnicity put him at greater risk of contracting COVID-19. This case has demonstrated that the risk reduction assessment may assist line managers implement appropriate adjustments for BAME employees in order alleviate their concerns and mitigate the risks of COVID-19. Line managers will also be required to consider circumstances that are local to the workplace and to make decisions by consulting with their employees and other key stakeholders. Occupational health services 
should be made available for employees to access for further support related to their underlying health conditions and/or psychological support [8]. Although progress has been made to include ethnicity as a risk factor within the risk reduction assessment, a more detailed level of understanding is needed urgently to ascertain the reasons why employees who identify as BAME have a higher prevalence of morbidity and mortality from COVID-19 infection within the UK.

In the current pandemic, it is very important to make clear that the role of ethnicity is of public health importance. Existing evidence indicates that there is an association between ethnicity and poor health outcomes following COVID-19 infection [9]. Globally, there are many health-care systems providing different levels of care for populations that are even more diverse; it is therefore of paramount importance to ensure that health-care employees of ethnic backgrounds are adequately risk-assessed so that the public health message is one that includes the needs of communities that are often marginalized and diverse [10-12]. The limitation of a single case study is that it is often viewed as lacking size to be generalizable to other cases [13]. However, the details provided in this case report will hopefully enable clinicians/managers to draw conclusions about the applicability of these findings to their own situation.

\section{Statement of Ethics}

The employee gave written consent to share his case.

\section{Conflict of Interest Statement}

The author declared no potential conflicts of interest with respect to the research, authorship, and/or publication of this article.

\section{Funding Sources}

The author received no financial support for the research, authorship, and/or publication of this article.

\section{References}

1 Khunti K, Singh AK, Pareek M, Hanif W. Is ethnicity linked to incidence or outcomes of covid-19? BMJ. 2020;369:m1548.

2 Docherty AB, Harrison EM, Green CA, Hardwick $H$, Pius R, Norman L, et al. [Internet]. Features of 16,749 hospitalised UK patients with COVID-19 using the ISARIC WHO Clinical Characterisation Protocol. 2020 [cited 2020 Jun 23]. Available from: https://www. medrxiv.org/content/10.1101/2020.04.23.20 076042v1.

3 Platt L, Warwick R. Are some ethnic groups more vulnerable to COVID-19 than others? Institute of Fiscal Studies, Nuffield Foundation. 2020 [cited 2020 Jun 23]. Available from: https: //www.ifs.org.uk/inequality/are-someethnic-groups-more-vulnerable-to-covid19-than-others/.

4 Chetty L. Equality and diversity: what physiotherapists need to know? Occup Health Physiother. 2016;2(20):14-7.
5 Cook T, Kursumovic E, Lennane S. [Internet]. Exclusive: deaths of NHS staff from covid-19 analysed. 2020 [cited 2020 Jun 23]. Available from: https://www.hsj.co.uk/exclusive-deathsof-nhs-staff-from-covid-19-analysed/7027471. article.

6 GOV.UK. [Internet]. Ethnicity facts and figures: NHS Workforce. 2020 [cited 2020 Jun 23]. Available from: https://www.ethnicityfacts-figures.service.gov.uk/workforce-andbusiness/workforce-diversity/nhs-workforce/latest\#by-ethnicity.

7 Public Health England. [Internet]. Disparities in the risk and outcomes of COVID-19. 2020 [cited 2020 Aug 24]. Available from: https://assets.publishing.service.gov.uk/government/ uploads/system/uploads/attachment_data/ file/908434/Disparities_in_the_risk_and_outcomes_of_COVID_August_2020_update.pdf.

8 Ranka S, Quigley J, Hussain T. Behaviour of occupational health services during the $\mathrm{CO}$ VID-19 pandemic. Occupational Med. 2020; 70(5):359-63.
9 Pan D, Sze S, Minhas JS, Bangash MN, Pareek $\mathrm{N}$, Divall $\mathrm{P}$, et al. The impact of ethnicity on clinical outcomes in COVID-19: a systematic review. EClinical Medicine [published online 2020 Jun 3]. Available from: https://www. thelancet.com/pdfs/journals/eclinm/ PIIS2589--5370(20)30148--6.pdf.

10 Koh D. COVID-19 lockdowns throughout the world. Occupational Med. 2020;70(5): 322.

11 Lan F-Y, Fernandez-Montero A, Kales SN. COVID-19 and healthcare workers: emerging patterns in Pamplona, Asia and Boston. Occupational Med. 2020;70(5):340-1.

12 Ross M, Singh T. COVID-19: an occupational health view from South Africa. Occupational Med. 2020;70(5):344.

13 Chetty L. An evaluation of the health and wellbeing needs of employees: an organizational case study. J Occup Health. 2017;59(1): 88-90. 